\section{A. ARS BILDUMA ISSN 1989-9262 UPV/EHU Pres} ARSBILDUMA (CC BY-NC-ND 4.0)

https://doi.org/10.1387/ars-bilduma.20394 BIBLID [(2019), 9; 67-76]

Recibido: 15/11/2018 Aceptado: 23/05/2019

\section{JOSÉ MANUEL CRUZ VALDOVINOS}

Universidad Complutense de Madrid

Facultad de Geografía e Historia

Planta 9, despacho 13

Profesor Aranguren, s/n

28040, Madrid (Madrid)

josemanuelcruzvaldovinos@ghis.ucm.es

ORCID: 0000000328015311

\title{
PLATERÍA GUIPUZCOANA: CAJA PARA LLEVAR LOS ÚLTIMOS SACRAMENTOS DE ANTONIO USARRALDE
}

\author{
SILVERWARE FROM GUIPUZCOA: BOX TO CARRY THE LAST SACRAMENTS \\ MADE BY ANTONIO USARRALDE
}

ORFEVRERIE DE GUIPÚSCOA. BOITE Á PORTER LES DERNIERS SACREMENTS
DE ANTONIO USARRALDE

\section{RESUMEN}

En la platería religiosa guipuzcoana existen unas piezas peculiares, unas cajas para colgar al cuello cuyo interior contiene un recipiente para Hostias consagradas y otro para el óleo de los enfermos. Estudiamos su etimología, tipología y difusión, y añadimos a su corto catálogo un ejemplar especialmente bien conservado y completo aparecido en una subasta madrileña $\mathrm{Su}$ autor es el platero tolosano Antonio Usarralde, activo en la segunda mitad del siglo XVIII, contraste y marcador desde 1760 y autor de una docena de obras, de las que tres son dadas a conocer en este trabajo.

PALABRAS CLAVE

Platería de Tolosa; cajas para últimos sacramentos; Antonio Usarralde; marcador; siglo XVIII.

\section{ABSTRACT}

Within the religious silverware of Guipuzcoa there are some peculiar objects: Boxes meant to be hung from the neck which bear inside a container for hosts and another one for the oil used for the anointing of the sick. This article deals with this piece's ethimology, typology and its spreading, and we add to its short catalogue a particularly well-preserved and complete piece which turned up in an auction in Madrid. Its author is Antonio Usarralde, a silversmith from Tolosa who was active during the second half of the 18 th century, working as a hallmarker and marker since 1760 and who produced some dozen pieces, out of which three will be introduced in this article.

KEYWORDS

Silverware of Tolosa; Box to carry last Sacraments; Antonio Usarralde; hallmarker; $18^{\text {th }}$ century.

\section{RÉSUMÉ}

Dans l'orfèvrerie religieuse de Guipuscoa, on trouve des pièces particulières, des boîtes à porter en pendentif, dont l'intérieur contient un récipient à hosties et un autre à huile des malades. Nous étudions son étymologie, sa typologie et sa diffusion, et en ajoutons à son catalogue restreint un exemplaire particulièrement bien conservé et complet, paru lors d'une vente aux enchères à Madrid. Son auteur est le maittre orfèvre tolosan Antonio Usarralde, actif pendant la seconde moitié du XVIIIe siècle, essayeur depuis 1760 , ainsi qu'auteur d'une douzaine d'œuvres, dont trois sont publiées dans cet article.

\section{MOTS-CLÉS}

Orfèvrerie de Tolosa; boites à porter les derniers sacrements; Antonio Usarralde; essayeur; XVIII siécle. 


\section{INTRODUCCIÓN}

Ha aparecido recientemente en el comercio madrileño una pieza poco común marcada por el platero guipuzcoano Antonio Usarralde. Con tal ocasión hemos realizado una investigación tipológica y en torno a este artífice con las conclusiones que damos a conocer a continuación.

\section{LAS CAJAS PARA LLEVAR LOS ÚLTIMOS SACRAMENTOS}

La pieza figuró en dos catálogos, pues fue subastada dos veces en un espacio menor de un año. Los catálogos respectivos la describen como "Portaviático de plata en forma de capilla de medio punto rematada por cruz. S XVII-XVIII. Marcas de platero. $17 \times 3 \times 10 \mathrm{~cm}^{\prime \prime}$. (Fig. 1). Conviene que hagamos una descripción más precisa. La pieza, de planta rectangular $(10 \mathrm{x}$ $3 \mathrm{~cm}$ ) y $17 \mathrm{~cm}$ de altura, está dividida en dos cuerpos. El superior, de mayor altura, termina en medio punto y encima lleva una crucecita latina de brazos en diedro y remate de bolillas; tiene una puerta, lisa por dentro y por fuera, con bisagra que se abre hacia la derecha, que permite el acceso al interior donde existe una moldura cilíndrica en que encaja una cajita con tapa desmontable, que sirve de receptáculo para la Sagrada Forma. En el cuerpo inferior hay una puerta similar adornada por un espejo ovalado ahuecado por dentro; el interior se divide verticalmente en tres partes, la central horadada, de doble anchura que las laterales, que son cerradas; en la cavidad se aloja un cajoncito con espejo en la delantera, en él se guarda un cilindro para llevar el óleo de los enfermos. Ambas puertecillas cierran con pasadores sujetos con cadenillas y el cuerpo superior lleva sendas anillas para sujetar un cordón con la que el sacerdote llevaría la pieza colgada del cuello. Toda ella es de plata en su color excepto el depósito para la Hostia consagrada, que está dorado. (Fig. 2).

La obra lleva hasta cuatro marcas iguales, tres por el reverso y otra en el reverso de la portezuela inferior: USAR/RALDE, con letras de trazo grueso. (Fig. 3).

1 Goya Subastas Madrid, 11-12-2017, lote 244 estimación 1200/1500 e, Goya Subastas, Madid 17-102018, lote 553; estimacion 900/1200 e. Procede de un propetario particulas, no de una igleshe producen dos fotografías, una con la pieza cerrada y otra con ella abierta, extraída la cajita de la parte superior y el cajoncito de la inferior. Agradecemos a Mariano Blasco de Bustos, director general, su atención y que nos haya proporcionado las fotografías que aparecen en este trabajo.

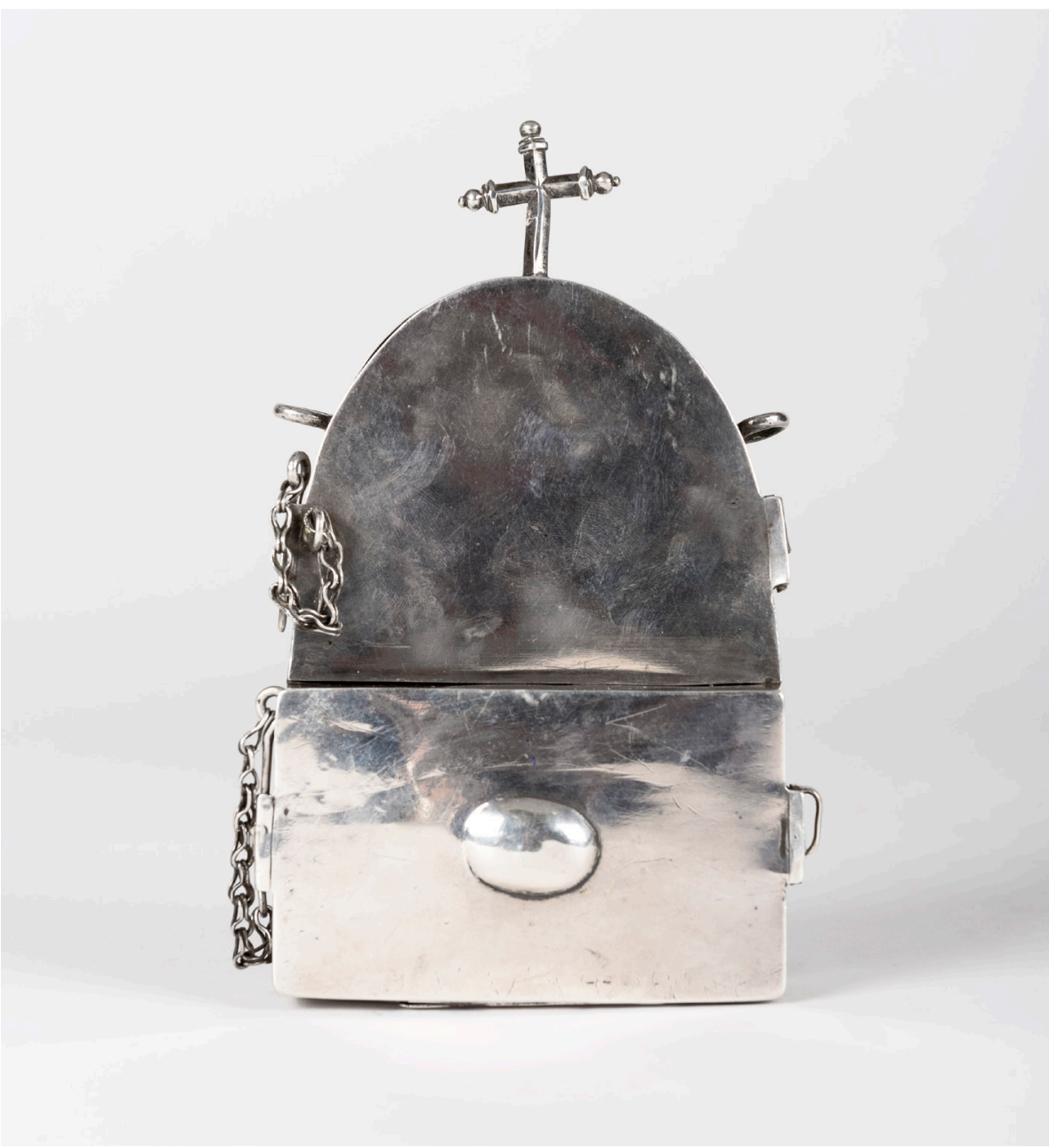

Fig. 1: Caja para llevar los últimos sacramentos. Colección privada. Antonio Usarralde. 1750/1760 


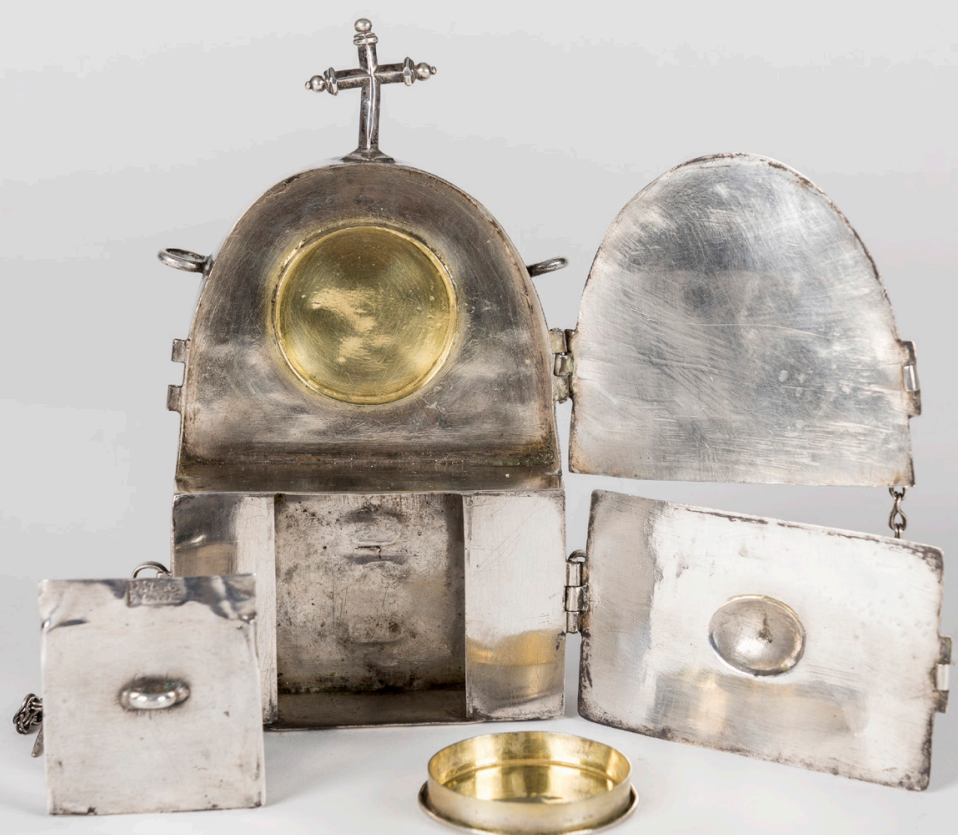

Fig. 2: Caja para llevar los últimos sacramentos. Colección privada. Antonio Usarralde. 1750/1760. Detalle de caja abierta y desmontada

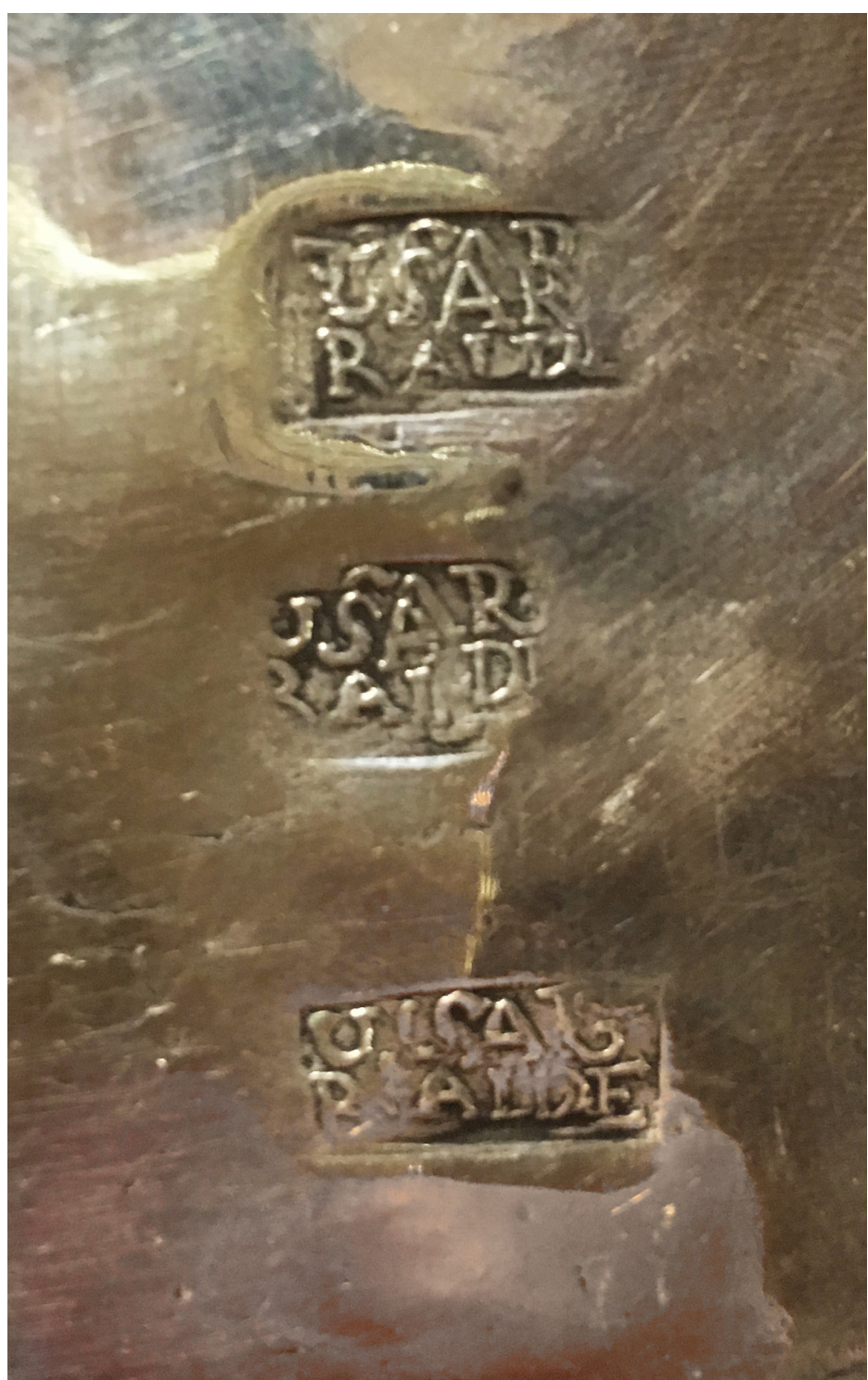

Fig. 3: Caja para llevar los últimos sacramentos. Colección privada. Antonio Usarralde. 1750/1760. Marcas de la caja. Antonio Usarralde 
Ignacio Miguéliz dio a conocer tres ejemplares del mismo tipo que el ahora presentado denominando a cada uno de ellos portaviáticos en plural $^{2}$. No menciona su uso como crismera, ni en la denominación ni en la descripción. Todos se localizan en iglesias: San Miguel de Artadi (Zumaia), $12 \mathrm{~cm}$ de altura, 7,5 x 2,5 cm de base, sin marcas y que data a mediados del siglo XVII; San Nicolás de Bari (Orio), $10 \mathrm{~cm}$ de altura, 7,5 x $3 \mathrm{~cm}$ de base, marca de Juan de Arenas el Mozo, platero de Azpeitia (+1676), a pesar de lo cual data la pieza en el último cuarto del siglo XVII; San Martín de Tours (Errezil), $15 \mathrm{~cm}$ de altura, $7.5 \times 4 \mathrm{~cm}$ de base, sin marcas, pero que el autor citado atribuye a Antonio Virón (+1736), platero también de Azpeitia; lo data en 1726 porque en esa fecha le pagó la iglesia parroquial 285 reales por dorar y componer varias piezas ${ }^{3}$. Sin ficha ni fotografía, señala que existen otras piezas semejantes en Andoain -como la de Zumaia- y Zaldibia ${ }^{4}$

La descripción que hace Miguéliz de las citadas piezas es diferente a la que hemos realizado respecto a la pieza subastada en Madrid: "Cajas rectangulares con el perfil superior semicircular y el inferior con un cajón rectangular, que tiene el frontal abatible para dar paso a una caja cilíndrica donde se guarda la Sagrada Forma" ${ }^{\text {. No hemos }}$ conocido directamente estas piezas, pero basta ver las fotografías para apreciar las anillas, los pasadores y las cadenillas tanto en el cuerpo superior como en el cajón inferior. Nos extraña que la caja para la Hostia esté en el cajón y que no se indique nada del cuerpo superior, como si no tuviera cavidad alguna y fuera un elemento simplemente decorativo, aún cuando se observan los elementos de apertura y cierre tal y como describimos en el ejemplar de la subasta madrileña. Por todo lo cual, nos atrevemos a pensar que son piezas de estructura semejante a esta última. Es posible que se haya perdido el tubo del óleo de enfermos y también la cajita original para la Hostia y que, por eso, se use actualmente el cajoncillo como teca para esta última.

2 MIGUÉLIZ VALCARLOS, I.: Zilargintza gipuzkoan XV.-XVIII Mendeak, San Sebastián 2008 (Diputa ción Foral de Guipuzcoa), edición en vasco y español, pp., 576-577, nºs 345, 346, 347, con fotografía que los presenta cerrados.

3 MIGUÉLIZ VALCARLOS, I.: op. cit., pp. 380-381. Por errata anota que la pieza de la iglesia parroquial de Azpeitia le encargó en 1737 la guarnición de la pila bautismal en la que recibió el sacramento san Ignacio; cobró la realic gnacio; cobro la reajzion de la obra acabada por Mu errata por 1737, pues afirma que la terminó tras la muerte de su maestro.

4 MIGUÉLIZ VALCARLOS, I.: op. cit., p. 247, notas 48 y 49. La fotografía incluida corresponde a la pieza de Orio, de la que se lee la inscripción, aunque el pie de foto indica "Zaldibia".

5 MIGUÉLIZ VALCARLOS, I.: op. cit., p. 247.
Los ejemplares cuya fotografía publica Miguéliz tienen decoración grabada en su frente. Los de Zumaia y Orio, un cáliz con una hostia encima, y el último, además, un adorno de eses a los lados y en el cajoncito; tanto el cáliz como la cruz de remate (perdida en el de Orio), son propios del siglo XVII. La pieza de Errezil tiene cruz sobre querubín según modelos del XVIII y el frente se adorna en el centro con un pequeño busto de Cristo (no el Padre eterno) bendiciendo con la diestra y en la izquierda el mundo rematado en cruz, rodeado de un cerco de sendos ocho rayos grabados alternando rectos y flameantes. Las dos piezas más antiguas tienen espejos ovalados sobresalientes en el cajoncito inferior, tal como ocurre en la que presentamos.

Señala Miguéliz con acierto que es un tipo de pieza propio de Gipuzkoa. Desde luego, no lo conocemos en Navarra ni en Bizkaia, y menos en otras partes del territorio peninsular. En San Pedro de Uncella (Álava) se conserva una pieza semejante aunque carece de cajoncillo; en el cuerpo superior va adosada la caja cilíndrica con tapa que sirve para guardar la Hostia y la puertecilla cierra con un pasador, ahora perdido, como la cruz de remate; tiene anillas laterales para pasar el cordón con que colgarla al cuello. El catálogo alavés comenta que quizá llevaba también un recipiente para el óleo de los enfermos, pero no parece que hubiera tenido cajón alguna vez, aunque hay espacio suficiente para colocar una pequeña caja o crismera para óleo ${ }^{6}$.

Estas piezas se han denominado "portaviático" por Munoa y "portaviáticos" -en pluralpor Miguéliz. La palabra viático, según la definición de la Real Academia Española significa "sacramento de la eucaristía que se administra a los enfermos que están en peligro de muerte". En una acepción vulgar, solía denominarse "viático" a la procesión en que los vecinos acompañaban al sacerdote por las calles de la localidad para que administrara la Comunión a los enfermos, que así cumplían con la obligación de comulgar por Pascua. Estas piezas incluyen un recipiente de las Hostias capaz para contener varias de ellas, por lo que es posible que, en tiempos no demasiado pretéritos, se hubieran usado para esa ceremonia, Pero la denominación de portaviático debe rechazarse, por no ser capaz de sugerir la doble función que cumplían las especies que albergaban estas piezas: por un lado, la hostia, destinada a la Comunión, y por otro, el óleo de los enfermos para la Extremaunción encerrado en la ampolla del cajoncito inferior.

6 PORTILla VITORIA, M. J.: Catálogo monumental. Diócesis de Vitoria. Los valles de Aramayona y Gamboa: por Ubarrundia a la llanada de Álava, VIII, Vitoria 2001, p. 708 y lám. 524. 
La Extremaunción es la unción con el óleo consagrado de las personas que se hallan en peligro de muerte por enfermedad o por ser muy ancianas y tiene por finalidad darles fuerza para el último paso y, en su caso, curar su dolencia. Era y es costumbre, dar de comulgar a los enfermos lúcidos tras administrarles la Extremaunción, por lo que solía hablarse de "los últimos sacramentos", pues, aunque correspondían a liturgias distintas, se administraban sin solución de continuidad. Nos parece más apropiada, por tanto, para estas piezas, la denominación de caja para llevar los últimos sacramentos.

Conviene destacar que los artífices que marcan las obras mencionadas conocidos por ahora son de las villas de Azpeitia y de Tolosa, y que las localidades donde se encuentran las obras se ubican en su proximidad. Zumaia y Orio al norte en la costa, Andoain muy cerca de Tolosa y Errezil entre ambas. Pensamos, en el estado actual de la cuestión, que ni siquiera fueron piezas usuales en toda Gipuzkoa, sino en un territorio más reducido, delimitado por los municipios citados. Aunque Miguéliz encuentra explicación al tipo en la lejanía de los caseríos en que residían muchos feligreses de Gipuzkoa ${ }^{7}$, estas circunstancias se producían igualmente en el resto de los territorios vascos y en el norte de Navarra. Estas cajas serían usadas igualmente dentro de los núcleos de población, pues siempre habría recorrido entre la iglesia y la casa del enfermo. En nuestra opinión, el tipo fue ideado en el siglo XVII en Tolosa o Azpeitia, donde existían algunos plateros asentados, e hizo fortuna en las cercanías, por lo que se repitió durante bastantes años, aunque por ahora no parece que alcanzara difusión fuera de alli.

\section{EL PLATERO ANTONIO USARRALDE}

La marca de platero que aparece en la pieza que comentamos fue publicada por primera vez por Rafael Munoa en 1984, que lo identificó como "Usarralde" y la incluyó entre las marcas de Vitoria-Gasteiz ${ }^{8}$. Aparecía fotografiada, no existían otras marcas en la pieza y, según se indica, se hallaba en un portaviático en colección particular, que sin duda debió de ser el mismo que se ha subastado en Madrid. La razón por la que Munoa clasificó la marca como vitoriana debió de ser que el apellido de este platero aparecía -con otra marca diferente- en dos piezas distintas, un cáliz y una naveta en colección particular, junto a la que interpretó

Miguéliz VALCARLOS, I: op. cit., p. 247. Indica que la función de estos portaviáticos era la de "llevar el viático a los caseríos, ya que no olvidemos muchas de las iglesias guipuzcoanas tenían a sus feligreses residiendo en caseríos alejados del núcleo central de la población".

8 FERNÁNDEZ, A., MUNOA, R., RABASCO, J.: Enciclopedia de la plata española y virreinal americana Madrid, 1984, p. 239, n 1458 como marca de localidad de Vitoria-Gasteiz y la de un platero que identificó como José de Legarda . En ambas ocasiones, indicó que el platero era Antonio de Usarralde y el marcador -que llamó contraste- José de Legarda9 ${ }^{9}$. Por último, mencionó a Antonio de Usarralde en la relación de plateros de Vitoria-Gasteiz con la fecha de $1764^{10}$. Además, incluyó entre las marcas donostiarras las que lleva un cáliz en colección particular, que era la misma que las del cáliz y naveta citados -VSARAL-, junto a las que identificó como de San Sebastián y de Legarda, que aquí llamó Juan, considerando a Usarralde contraste y a Legarda platero ${ }^{11}$.

Miguéliz se ocupó de este platero -a quien siempre denomina Usaralde- ampliamente y mencionó noticias sobre su actividad desde 1746 a 1765, en su mayoría relativas a arreglos o dorado de piezas para iglesias en cuyos libros de fábrica aparecen los pagos, aunque también algún encargo de hacer piezas nuevas. En 1746 cobró 495 reales por dorar tres cálices con sus patenas y un copón y hacer nuevos los vasos o copas de dos cálices (Arriaran) y 52 reales por dorar un copón (Alkiza); en 1747, 1402 reales y 27 maravedís además de cierta plata vieja por hacer un copón, crismeras, vinajeras y portapaz para Abaltzisketa; en 1749, 90 reales por dorar cálices y patena en Alkiza; en 1758, 44 reales por componer varias alhajas (Altzo Azpi); en 1759, 20 reales por aderezar un candelero y 16 reales por componer una cruz (Asteasu); en 1760, 150 reales por renovar un copón (Anoeta) y 30 reales por el arreglo de una cruz; en 1762, 570 reales por hacer la cruz de un estandarte (Larraul); en 1763, 60 reales por la composición de una cruz (Ametzketa) y en 1765, 120 reales por dorar un copón y renovar pectoral y crismeras (Olaberria) ${ }^{12}$. Todas estas localidades se hallan cercanas a Tolosa. En 1760 fue elegido marcador y contraste de la provincia, oficio en que permaneció hasta 1788 , aunque es posible que ejerciera solo hasta 1785 . Se le dispensó de acudir a la Corte para ser examinado, dados su edad y estado de salud, y lo hizo en 1763 ante Manuel José de Sancho, contraste de Bilbao ${ }^{13}$.

Un error de clasificación en la Enciclopedia indujo a Miguéliz a afirmar que "residió durante una temporada en Vitoria-Gasteiz, como lo demuestra el hecho de encontrar su marca junto al punzón de localidad de dicha ciudad y al de autor de José de Legarda en un cáliz de San Sebastián"14. Se trata de un cáliz rico que pertenece actualmente a la basílica de

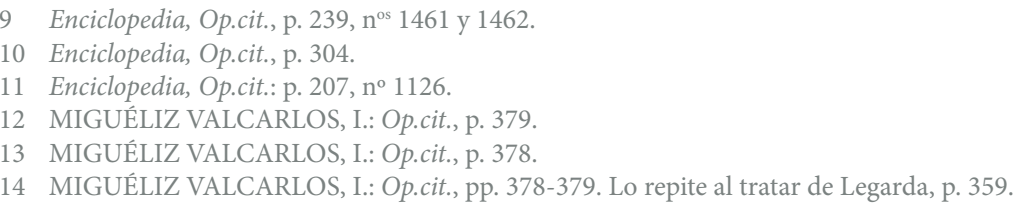


Santa María del Coro de la ciudad donostiarra a la que fue donado por el propio Munoa, y que figuraba aún en la Enciclopedia como en colección particular. Esta pieza y sus marca fueron registradas doblemente por su entonces propietario, primero con el número 1126 (con Usarralde y Legarda, acompañadas de la considerada marca de San Sebastián) y después con el número 1461 (la considerada marca se indica como de Vitoria-Gasteiz) ${ }^{15}$. La fotografía de la supuesta marca que correspondería a la ciudad de Vitoria-Gasteiz o a la de San Sebastián es oscura y borrosa. Miguéliz también reproduce las tres marcas y la que considera de San Sebastián es en la fotografía inidentificable y no nos parece que pueda ser Vitoria-Gasteiz o San Sebastián ${ }^{16}$. No es coherente que Usarralde hubiera podido ejercer como marcador de Vitoria-Gasteiz, que tuvo sus propios marcadores, ni que él y Legarda, que actuaba en el entorno de San Sebastián y de Tolosa, se trasladaran simultáneamente a Vitoria-Gasteiz, donde no se ha localizado un solo documento que hable de ellos.

Pasamos a continuación al estudio de las marcas de Antonio Usarralde. Según Miguéliz, se conocen dos marcas diferentes del platero. USARRAL/DE, en mayúsculas y en dos líneas, respecto a la que señala que la utilizó como autor y como contraste ${ }^{17}$ y la que transcribe como USAR/RALDE, también en mayúsculas y en dos líneas ${ }^{18}$. No proporciona referencias temporales al respecto.

Por nuestra parte, diferenciamos tres marcas de este platero. La que consideramos más antigua es USAR/RALDE, dada a conocer por Munoa y a la que se refiere Miguéliz en segundo lugar; tiene letras mayúsculas de trazo grueso y diseño irregular. La $\mathrm{R}$ del final de la primera línea termina en una larga pata semicircular y es muy diferente de la R que encabeza la segunda línea. Tiene un marco rectangular. La segunda marca es la primera mencionada por Miguéliz ${ }^{19}$, VSARRAL/DE, unidas AR, AL y DE. Las letras son menores que en la otra marca, más cuidadas y de trazo correcto y el marco, quebrado, se ajusta a la extensión de las líneas. Existe una tercera marca, VSARAL/DE, no mencionada por Munoa

15 Enciclopedia, op. cit., p. 207, no 1126 y p. 239, nº 1461

6 MIGUÉLIZ VALCARLOS, I.: op. cit., p. 405. La coloca entre las marcas de Vitoria.

17 MigUÉLIZ VALCARLOS, I.: op. cit., p. 379. Como autor la localiza en un copón para Hernialde y en las crismeras de Aduna; como contraste, en un cáliz de Zerain obra de José de Larreta y en las crismeras de Deba, que indica obra de José de Legarda.

18 MIGUÉLIZ VALCARLOS, I.: op. cit., p. 379. No indica si la usó como artífice, como contraste o en ambos casos. El autor la localiza en un cáliz de Ezcurra, un copón en Areso y una custodia de Saldías, las tres localidades en Navarra, en las crismeras de Baliarrain y un portapaz del santuario de Itziar de Deba en Gipuzkoa.

19 MIGUÉLIZ VALCARLOS, I.: op. cit., p. 401. La transcripción de esta marca en la publicación es incorrecta, pues la inicial no es $\mathrm{U}$ sino $\mathrm{V}$ y no señala la fusión de letras. ni por Miguéliz aunque éste la reproduce en fotografía. El diseño de letras es de menor tamaño que en la anterior (salvo la S, mayor), más tosco y no une las letras, excepto DE presenta terminación semicircular para cobijar la segunda línea ${ }^{20}$.

Examinamos a continuación las obras documentadas o marcadas por Antonio Usarralde, diferenciando según su marcaje.

\subsection{Piezas documentadas sin marca}

Se conocen piezas que están documentadas por Miguéliz como pagadas a Usarralde y que no llevan marca. Son seguramente las más antiguas de su producción pues los pagos aparecen en $1747^{21}$ : copón (San Juan Bautista de Abaltzisketa), que Miguéliz fecha en 1749 quizá por errata ${ }^{22}$; vinajeras con salvilla (San Juan Bautista de Abaltzisketa). Miguéliz las considera de estaño, pero son de plata y, por su estilo, las que se pagaron a Usarralde en $1747^{23}$

\subsection{Marca USAR/RALDE}

La marca que consideramos más antigua, USAR/RALDE, se encuentra en las siguientes obras y no va acompañada de ninguna otra marca: par de cálices (iglesia parroquial de Nuestra Señora de la Asunción de Ezcurra, Navarra) ${ }^{24}$; copón (Iglesia parroquial de Nuestra Señora de la Asunción de Areso, Navarra) ${ }^{25}$; custodia (Iglesia parroquial de San

20 Que sepamos, sólo aparece en un cáliz de Zerain y en unas crismeras de Nuestra Señora de la Asunción de Deba. Las dos reproducciones fotográficas, en MIGUÉLIZ VALCARLOS, I. op. cit., p. 393.

21 MIGUELLIZ VALCARLOS, I.: op. cit., p. 379

22 MIGUÉLIZ VALCARLOS, I.: op. cit., p. 528, no 216, 25, 13, $12 \mathrm{~cm}$. Es un copón liso, de copa anch y poco profunda, con tapa ligeramente moldurada y rematada en un pequeño cuerpo cilíndrico con galloncitos y bola. El nudo es de jarrón y va sobre pie de doble moldura y gollete cilíndrico.

23 MIGUÉLIZ VALCARLOS, I.: op. cit., p. 379 y p. 581 , nº 358 . Jarritos: $12,7,5,4 \mathrm{~cm}$; salvilla: $25.5,16,5,2 \mathrm{~cm}$ Tienen cuerpo largo y ligeramente abombado en su base, asa de ce con ramales, pico adosado muy saliente sobre cartela, cubierta de cúpula ligeramente bulbosa rematada en un saliente a modo de flor con un aro encima que encierra la inicial $\mathrm{A}$ o V. La salvilla tiene pequeño fondo y borde con contornos. Además de estas vinajeras y el copón anterior, hizo unas crismeras, y un portapaz, que no parece que se conserven.

24 GARCÍA GAINZA, M.C., ORBE SIVATTE, M., DOMEÑO MARTÍNEZ DE MORENTIN, A., AZAN

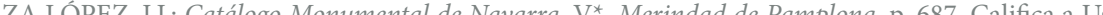

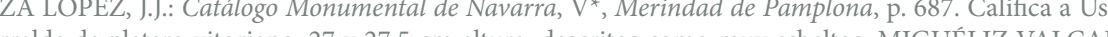
LOS, I., op. cit., p. 379, en la biografía del platero, se refiere a un solo cáliz.

25 Catálogo Monumental de Navarra, $\mathrm{V}^{*}$, op. cit., p. $198.34 \mathrm{~cm}$. Se indica que es liso y de estructura usua para la fecha y que bajo la cruz de remate incorpora una cabeza de querubín, de la que incluye un dibujo. 
Juan Bautista de Saldías, Navarra) ${ }^{26}$; crismera (Iglesia de Nuestra Señora de la Asunción de Baliarrain, Gipuzkoa) ${ }^{27}$; portapaz (Santuario de Itziar de Deba, Gipuzkoa) ${ }^{28}$; caja para llevar los últimos sacramentos (en el comercio madrileño).

\subsection{Marca VSARRAL/DE}

La marca VSARRAL/DE con perfil quebrado y letras AR, AL y DE fundidas, aparece en las siguientes piezas, sin coincidir con ninguna otra marca: arqueta de crismeras (Nuestra Señora de la Asunción de Aduna, Gipuzkoa) ${ }^{30}$; copón (Nuestra Señora de la Asunción de Hernialde, Gipuzkoa) ${ }^{31}$; naveta (Museu de Arte Antiga, Lisboa) ${ }^{32}$; cáliz (San Salvador de Legorreta, Gipuzkoa) ${ }^{33}$. (Figs. 4 y 5 )

26 Catálogo Monumental de Navarra, V**, op. cit., p. $577.43,3 \mathrm{~cm}$. Se cataloga en el siglo XVII aunque con la base quizá añadida en el XVIII.: Se describe con "base circular elevada, astil con cilindro inferior nudo ovoide y sol con alternancia de rayos rectos y flameados, los primeros culminados en estrellas y piedras. En la unión del astil y sol se disponen dos cabecitas de querubín". Se considera a Usarralde platero vitoriano.

27 MIGUÉLIZ VALCARLOS, I.: op. cit., p. 538, no $246.4,5 \times 3 \mathrm{~cm}$. Es una pequeña crismera de factura muy simple. Lleva la inscripción KRISMA OLEOA, pero tuvo que ser destinada en origen alóleo de los enfermos, pues lle de salir de la iglesia.

28 MIGUÉLIZ VALCARLOS, I.: op. cit., p. 576, no 344.16 × 10 x 4,5 cm. La pieza presenta una decoración muy profusa en el copete, con motivos de láureas, tornapuntas y querubín central; la figura de Crucificado lleva corona de espinas y paño por detrás, calavera y tibias al pie. En la basa, una roseta. Las columnas estriadas laterales acaban en plintos con cabeza de querubín igual a la del remate, una de ellas perdida.

29 Descrita en la primera parte de este trabajo.

30 MIGUÉLIZ VALCARLOS, I : op. cit, p. 534, no $233,16 \times 15 \times 6,5 \mathrm{~cm}$ Caja que lleva en su interior las tres crismeras. En su exterior, la caja se decora en los frentes con dos espejos verticales rodeados de motivos vegetales. Tapa ligeramente cóncava rematada en una cruz de diedros y terminación cónica que se eleva sobre monte en cuyos frentes coloca una cabeza de querubín. Patas de voluta con follaje.

31 MIGUÉLIZ VALCARLOS, I.: op. cit., p. 379. No incluye fotografía ni ficha, tan solo relaciona esta piez en la biografía del platero.

32 Museu d’Arte Antiga, Lisboa, no inv. 956.16 x 15,7 cm. No disponemos de fotografía. Debemos el conocimiento de su existencia a la doctora Pilar Nieva Soto, a quien agradecemos la noticia.

$3325,5,15,5,8 \mathrm{~cm}$. Plata sobredorada en la copa. La marca está impresa defectuosamente. Es liso, aunque muy correctamente trabajado y de proporciones armoniosas. Aparece reproducido un cáliz muy parecido de la misma sede en MIGUÉLIZ VALCARLOS, I. op cit. p. 517, no 182 aunque el autor afirma que no tiene marcas y las medidas que da son un poco diferentes $(23,5,14,8,8 \mathrm{~cm})$. Pensamos que es la misma pieza y que el autor no vio la marca, pues aparece al desenroscar el pie. Debemos su conocimiento y fotografías a Rafael Munoa, que nos las facilitó bastantes años antes de su muerte en 2012.

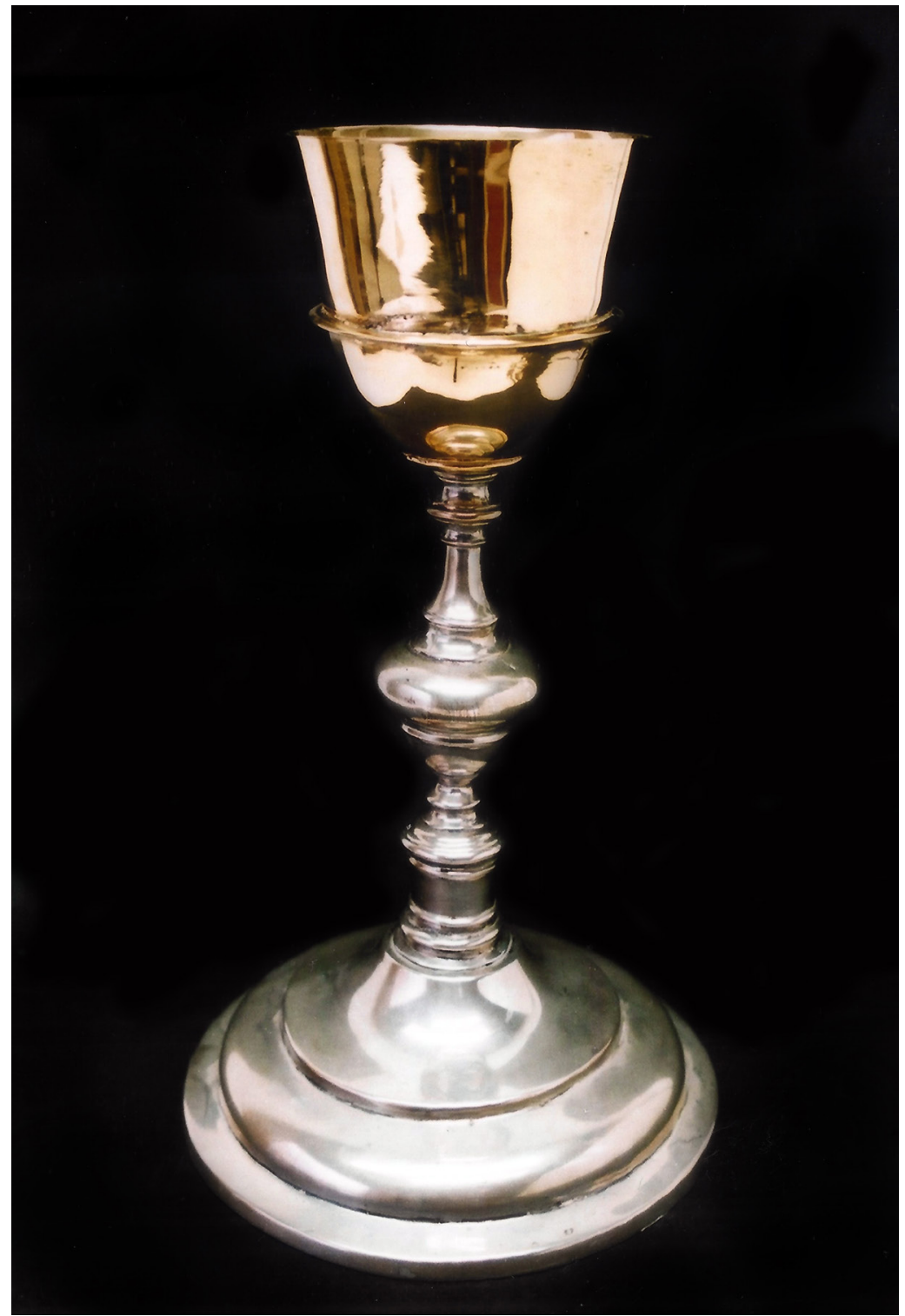

Fig. 4: Cáliz. San Salvador de Legorreta (Gipuzkoa). Antonio Usarralde. 1760/1765 


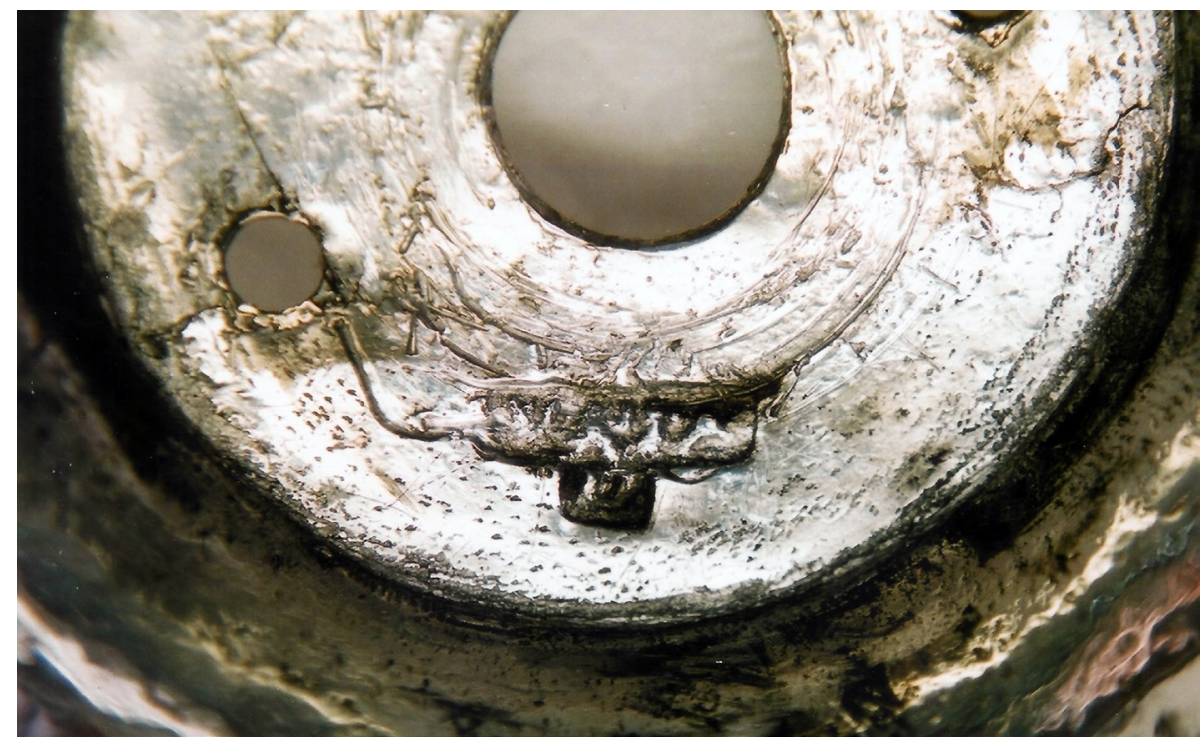

Fig. 5: Cáliz. San Salvador de Legorreta (Gipuzkoa) Marca del cáliz. Antonio Usarralde

\subsection{Marca VSARAL/DE}

La marca VSARAL/DE con perfil curvo en el borde inferior y letras DE fundidas aparece en las siguientes piezas, coincidiendo con las marcas de otros plateros: cáliz (Nuestra Señora de la Asunción de Zerain, Gipuzkoa). Con la marca de José Antonio de Larreta (renovación) 1761 ${ }^{34}$; crismeras (Nuestra Señora de la Asunción de Deba, Gipuzkoa). Con la marca del platero Juan de Legarda y otra marca cronológica, 1764, que sería impresa por Usarralde ${ }^{35}$; cáliz (Basílica de Santa María del Coro, San Sebastián). Con la marca del platero Juan de Legarda y un escudete cuyo motivo es imposible de distinguir ${ }^{36}$; salvilla (San Martín de Tours, Amasa, Gipuzkoa). Con la marca del artífice Juan de Legarda ${ }^{37}$; naveta (colección particular). Con la marca del artífice Juan de Legarda ${ }^{38}$.

34 MIGUELIZ VALCARLOS, I.: op. cit., p. 516, n 179. Documentada en 1761 la renovación de este cáliz por Larreta. Es sin duda la misma marca que aparece en las demás piezas que siguen a ésta, y la ligera diferencia que presenta respecto a la de las crismeras de Deba podría proceder de un deslizamiento al golpear el punzón.

35 MIGUÉLIZ VALCARLOS, I.: op. cit., p. 538, n 244. El artífice se identifica con José al no interpretar bien la abreviatura del nombre.

36 Enciclopedia, op. cit., p.207, nº 1126 y p. 239, nº 1461. En cada uno de los números aparece un juego de fotografías diferente de las marcas de Usarralde y Legarda, aunque se observa que ambas son las mismas. Quizá por ello se produjo la confusión. En el n 1461 , Legarda se identifica como contraste y Usarralde como artífice; en el no 1126, al contrario. MIGUÉLIZ VALCARLOS, I.: op. cit., p. 405, reproduce las marcas y se observa con claridad el escudete. Hace artífice a Usarralde y contraste a Legarda y considera al escudete marca de Vitoria-Gasteiz. El cáliz aparece fotografiado en el, no 389.

37 Enciclopedia op cit, p. 207, no 1128 . No hay fotografía de las marcas y el dibujo de la del marcador dice P.MAS, pero estaba muy frustra y se maquetó al revés. Si el dibujo de la marca es correcto, el artífice es, como se indica, Juan de Legarda.

38 Enciclopedia, op. cit., p. 239, nº 1462. No hay fotografía. Se identifica a José de Legarda como contraste y Usarralde como artífice. Además, incluye el dibujo de la marca de Vitoria, que dudamos de que exista en la pieza. 


\section{CONCLUSIONES}

En la primera parte del trabajo se analiza un tipo de pieza poco común, a la que hemos dado la denominación de "caja para llevar los últimos sacramentos" debido a su doble función de crismera y portaviático, que se localizan exclusivamente en zonas cercanas a Tolosa, donde debieron de originarse.

Dedicamos una segunda parte al estudio del platero Antonio Usarralde, autor de una caja para llevar los últimos sacramentos especialmente completa y bien conservada que damos a conocer en la primera parte. En especial, profundizamos en el análisis de su marcado tras establecer un completo catálogo de las piezas identificadas como suyas que se conocen por ahora.

Una primera conclusión que podemos establecer con seguridad respecto al marcado de este platero es que ejerció solamente como marcador y contraste en la villa de Tolosa, donde vivía, y que no usó marca de localidad, salvo que lo sea el escudete que aparece en el cáliz de Santa María del Coro de San Sebastián. Tampoco lo hicieron los marcadores y contrastes de la ciudad de San Sebastián en este tiempo.

La marca VSARAL/DE, que aparece en cinco piezas junto a las marcas de otros plateros, fue usada solamente en calidad de marcador. Cuando Usarralde imprimió su marca de marcador, parece que exigió al artífice de la pieza que imprimiera también su marca, pues existen cinco ejemplos de ello, lo que parece suficiente para afirmarlo. En cuanto al tiempo en que usó esta marca, sólo tenemos certeza de que lo hizo entre los años 1761 y 1764 pero, probablemente, lo hizo hasta el final de su actividad. El cáliz de Zerain está documentado en 1761 como obra del citado José de Larreta, cuya marca aparece en él. En esta fecha, Usarralde ya estaba nombrado marcador, aunque aún no había sido examinado. En las crismeras de Deba utiliza esta misma variante junto a la única marca cronológica que se le conoce, 1764, y Usarralde actúa de marcador porque el platero Juan de Legarda, que también imprime su marca, no fue contraste ni marcador. Nada podemos decir respecto a la fecha de las otras tres piezas que reúnen las marcas de Usarralde y Legarda, pues no están documentados y la actividad de Legarda se prolonga hasta 1786, por lo que ambos coinciden en el tiempo.

Las marcas USAR/RALDE y VSARRAL/DE debieron de ser usadas para las piezas labradas por Usarralde, pues no llevan otra marca que la suya. Hemos considerado más antigua la primera, sobre todo, a la vista del parecido formal de la segunda con la variante usada como marcador. 


\section{BIBLIOGRAFÍA}

FERNÁNDEZ, A., MUNOA, R., RABASCO, J.: Enciclopedia de la plata española y virreinal americana, Madrid, Ed. propia, 1984.

GARCÍA GAINZA, M.C., ORBE SIVATTE, M., DOMEÑO MARTÍNEZ DE MORENTIN, A., AZANZA LÓPEZ, J.J.: Catálogo Monumental de Navarra, V*, Merindad de Pamplona Pamplona, Gobierno de Navarra, Arzobispado de Pamplona, Universidad de Navarra, 1994

GARCÍA GAINZA, M.C., ORBE SIVATTE, M., DOMEÑO MARTÍNEZ DE MORENTIN, A., AZANZA LÓPEZ, J.J.: Catálogo Monumental de Navarra, V ${ }^{* *}$, Merindad de Pamplona Pamplona, Gobierno de Navarra, Arzobispado de Pamplona, Universidad de Navarra, 1996.

Goya Subastas. Madrid, 11-12-2017.

Goya Subastas, Madrid, 17-10-2018.

MIGUÉLIZ VALCARLOS, I.: Zilargintza gipuzkoan XV.-XVIII Mendeak, San Sebastián, Diputación Foral de Guipuzcoa, 2008.

PORTILla VITORIA, M. J.: Catálogo monumental. Diócesis de Vitoria. Los valles de Aramayona y Gamboa: por Ubarrundia a la llanada de Álava, VIII, Vitoria, Fundación Caja Vital, 2001. 